\title{
Effectiveness of solar fence in reducing human-elephant conflicts in Manchahalli village, Mysuru, Karnataka, India
}

\author{
G. Vibha ${ }^{1}$, H. G. Lingaraju ${ }^{1, *}$ and G. V. Venktaramana ${ }^{2}$ \\ ${ }^{1}$ Division of Environmental Sciences, Department of Water and Health-Faculty of Life Sciences, JSS Academy of Higher Education and Research, \\ Mysuru 570 015, India \\ ${ }^{2}$ Department of Studies in Environmental Science, Manasagangotri, University of Mysore, Mysuru 570 006, India
}

\begin{abstract}
Human-elephant conflict is not a new issue in the state of Karnataka, India. Primary conflict involves loss of lives on both sides, loss of property and damage to crops. Solar fencing is considered to be the most effective way to mitigate the conflict between humans and elephants. An assessment on the effectiveness of solar-powered fencing was carried out in Manchahalli village, which is located adjacent to Bandipur National Park (BNP), Karnataka and is prone to frequent raids by elephants. Hence, this area was chosen as the study site. Field survey was conducted between March and April 2019, to estimate whether the installation of solar fencing had reduced the damage caused by elephants on the crops. During the survey, questions related to the following factors were considered: area of land owned by farmers, distance from the forest boundary to the croplands, types of crops grown, types of crops damaged, year of installation of solar fence, damage caused to the solar fence, methods used before the installation of solar fencing and the perceived effectiveness of the solar fence. Among the 30 croplands that were surveyed, majority were at less than $2 \mathrm{~km}$ from the forest, followed by others ranging between 1 and $1.5 \mathrm{~km}$. Although solar fencing was not helpful in reducing the raids completely, it proved to be more effective than any other conventional method previously used.
\end{abstract}

Keywords: Croplands, field survey, human-elephant conflict, solar fence.

ELEPHANTS are large mammals of the family Elephantidae in the order Proboscidea. Three species are currently recognized: the African bush elephant (Loxodonta africana), the African forest elephant (L. cyclotis) and the Asian elephant (Elephas maximus). Asian elephants are listed in the 'Endangered' category in the IUCN/Red List (IUCN, 2008). One of the biggest threats to elephant populations is ivory $\operatorname{trade}^{1}$. Other threats to wild elephants include habitat destruction and conflicts with local people. The following four factors, viz. habitat, elephant

*For correspondence. (e-mail: lingarajuhg@jssuni.edu.in) population, elephant behaviour, and people contribute to initiating, escalating, or sustaining human-elephant conflicts (HECs) ${ }^{2}$.

Elephant crop raiding (i.e. the consumption of and/or damage to crops) is currently one of the most prevalent forms of HECs worldwide ${ }^{3}$. The on-going expansion of human settlements and activities, in addition to growing elephant populations outside protected areas in some localities ${ }^{4}$, has resulted in increased levels of interaction between people and elephants ${ }^{5}$. Crop raiding has direct impacts on human livelihoods, through the destruction of agricultural crops and nearby properties, as well as injuries to people and in some instances, death. Such impacts lead to negative perceptions of elephants by local communities, which in many cases strongly undermine conservation efforts targeted at the elephant populations ${ }^{6}$.

Some of the traditional mitigation measures to avoid HECs are crop-guarding, making noise and throwing stones, fire and repellants (e.g. chilli paste). Organized methods such as vehicle patrols and kumki elephants are also being used ${ }^{7}$. Elephant barriers such as wire fences, ditches, stone walls and solar fences are some common methods. Among all the mitigation measures, solar fences are the most effective in controlling conflicts with large mammals like elephants and $\operatorname{rhinos}^{8,9}$, and seem to be preferred by the local people ${ }^{10}$. The fences act as a physical as well as psychological barriers to separate elephants from settled areas ${ }^{11}$. The wires carry high-voltage current. The solar fencing gives a live but non-lethal shock to the intruder and creates fear against fence tampering. The alarm in the fencing system gets activated whenever the fence wire is disturbed by human beings and/or wild animals. The fence with alarm system is put in place only in sensitive areas to monitor crop damage and alerts the inhabitants of the protected areas. Elephants occasionally test the fences and may break through if the current is absent or low. Hence, the fence will have to be electrified every night. Sometimes, it may be necessary to electrify the fence all day. Once there is a breach in the fence, the elephant, having lost its fear of electricity, will try to do so again in the future ${ }^{6}$. In solar fencing, even if an animal is trapped in the fence, after 10 consecutive shocks the 


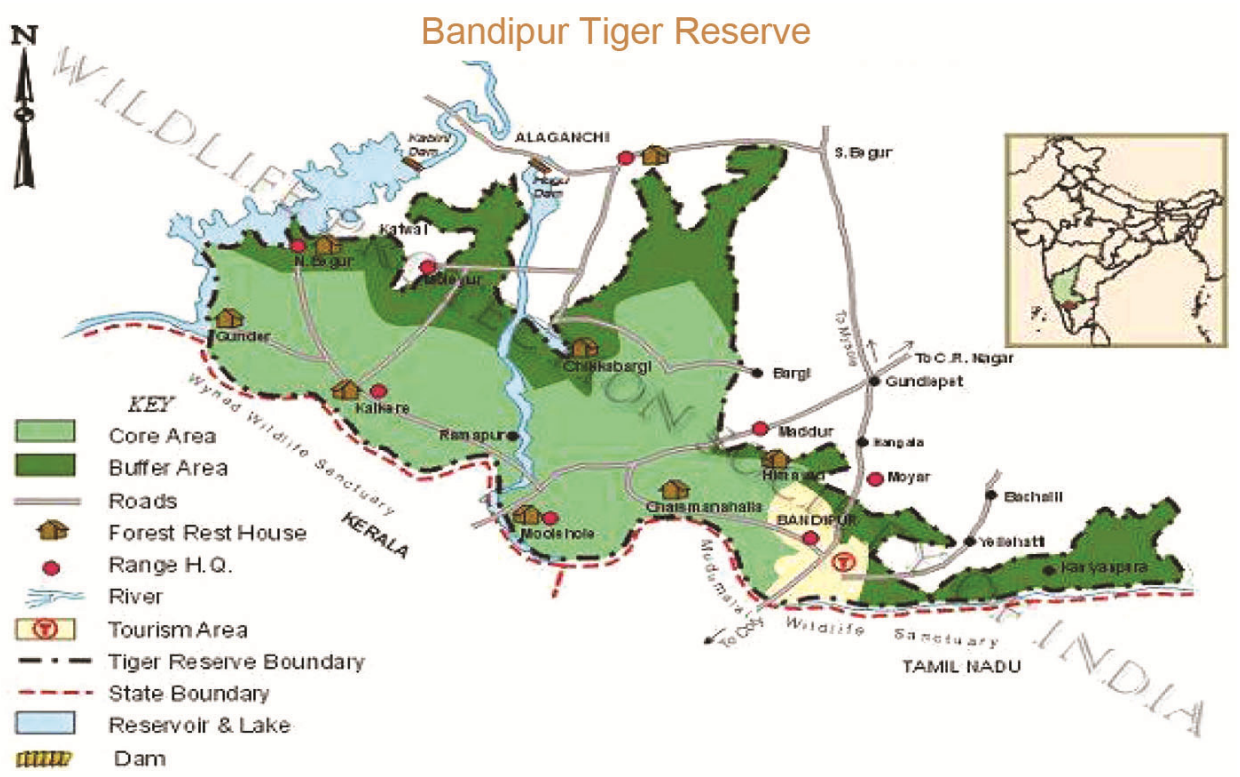

Figure 1. Map showing Manchahalli village in Chamarajanagar district, Karnataka, India.

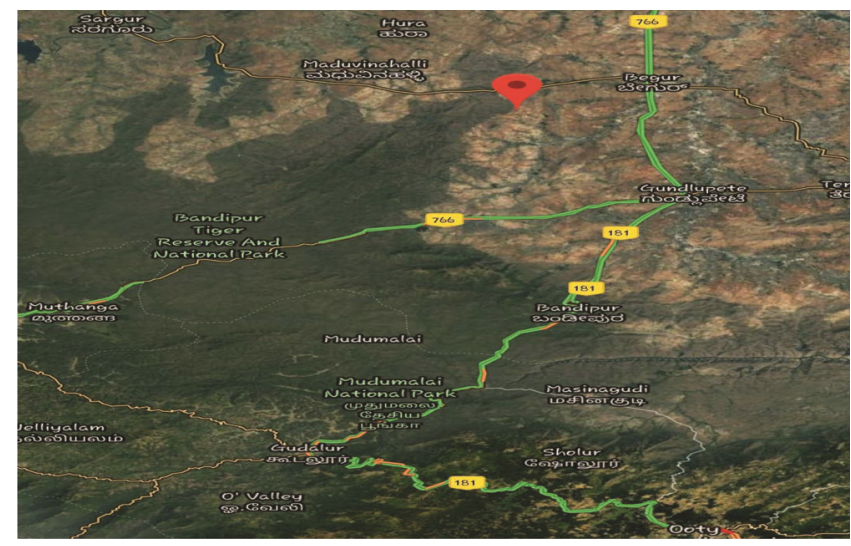

Figure 2. Satellite map of Manchahalli village.

system will trip and sound an alarm so that farmer can intervene, and no death is caused. Solar fences are easier and more cost-effective to install ${ }^{12}$. These are less expensive than conventional fences because they require less labour and lighter materials to set $u^{13}$. Solar fences can last for a long time - up to 40 years - when built with good-quality components and materials. With the above background we wanted to check the effectiveness of solar fences in reducing HECs.

\section{Study area}

The Bandipur National Park (BNP) is located between $75^{\circ} 12^{\prime} 17^{\prime \prime}-76^{\circ} 51^{\prime} 32^{\prime \prime} \mathrm{E}$ and $11^{\circ} 35^{\prime} 34^{\prime \prime}-11^{\circ} 57^{\prime} 02^{\prime \prime} \mathrm{N}$. The altitude of the park ranges from 680 to $1454 \mathrm{~m}$. BNP lies about $80 \mathrm{~km}$ from Mysore city in Gundlupet taluk, Chamarajanagar district, Karnataka, India (Figure 1).
Along with the Nagarhole National Park, BNP is one of the most important Tiger Reserves in the country. It is a part of the Nilgiri Biosphere Reserve, which covers an area of $2183 \mathrm{sq} . \mathrm{km}$. It is the largest habitat for elephants in Asia and the largest protected area in the southern part of India ${ }^{14}$.

Manchahalli village, where the survey was conducted, also belongs to the Gundlupet taluk. It has a population of around 1450 and agriculture is the main occupation in the village. Commonly grown crops include tomato, beans, banana, cotton and chilli. Many villagers depend on the rearing of cattle, sheep and goat for their livelihood. As it lies near the border of BNP, the village is prone to frequent human-elephant interactions. The study site was selected due to frequent issues of HECs since several years (Figure 2).

\section{Methodology}

The study was based solely on field observations and questionnaire surveys. A semi-structured questionnaire was prepared with the help of previously prepared questionnaires found in some journal articles, theses and several websites, and a set of questions for the survey was finalized in consultation with the Wildlife Conservation Foundation (WCF), Mysuru ${ }^{8,15}$. The questionnaire consisted of questions which were mainly related to the aspects of crops and solar fencing. The farmers were inquired about the distance of their cropland from the BNP boundary and the area of land owned by each farmer. They were asked about the types of crops grown currently and those destroyed during crop-raiding incidents. Methods employed prior to the use of solar fencing were 
noted. Farmers were asked about the effectiveness of the solar fencing and to compare its benefits with the previously used methods. Technical questions on the installation of solar fencing were asked, which included the voltage of the fencing, distance between poles and any damage caused to the poles. Additional information provided by the interviewees or farmers was also recorded. We also visited 50 households of the farmers who participated in the survey. We were able to conduct a survey on 30 croplands. Only sites which had solar fencing installed were visited and the owners were interviewed. Based on the reported cases of elephant raids, destruction of crops and damage to property, we visited the croplands randomly. The required data were collected through informal interviews and discussions with landowners and their family members. The data on crops grown, and crop loss was calculated based on the number of people cultivating the crops among the respondents, and it is represented in percentage.

\section{Results and discussion}

\section{Types of crops grown}

During the survey it was observed that about 15 types of crops were grown in the study village. Tomatoes were grown by most of the landowners $(25 \%)$, followed by chilli (18\%) and banana (14\%). Banana is a tropical crop and depending on the varieties, it can be cultivated in climates ranging from humid tropical conditions to mild subtropical conditions. Rainfall is most important for the growth of banana crops. Banana is mainly cultivated for its ripe fruits, vegetable and leaves. Coconuts are more useful compared to banana and provide diverse products to people ${ }^{16,17}$ (Figure 3). Among the people interviewed, 14 households had coconut plantations ranging from 10 to 115 in number and included young trees as well as those bearing mature coconuts. Tomato is the preferred crop in this region because of its ability to withstand high temperatures and since it is a warmseason crop. It requires low to medium rainfall. Like tomato, chilli also requires warm and dry weather. Chillies cannot withstand a lot of water. Heavy rainfall and stagnant water rot the plants. Although there was low rainfall during our survey, it was observed that these crops were grown with the extensive pumping of underground water.

\section{Types of crops damaged}

The reason for the high damage rate in case of banana is likely due to its higher fibre content and palatable, juicy stem. It is easy for raiding elephants to gather crops such as banana because of its tough tree-like pliable stem which is composed of the sheathing twisting leaf bases and which contains fibres of sufficient strength to keep the tree upright ${ }^{18}$. According to a survey conducted in southeastern Sri Lanka, banana crops were the most damaged in this region. A study in three reserve forests of Lakhimpur district, Assam and Karanodai block of Coimbatore district, Tamil Nadu also showed similar results $^{7}$. Banana was available throughout the year, and hence sustained greater cumulative damage than seasonal crops $^{19}$. If the elephants do not find crops such as the ones mentioned above, they raid permanent crops like coconut and jackfruit ${ }^{6}$. This usually happens when elephants do not find crops in their usual route of movement $^{20}$. Chilli plants were destroyed by trampling. Elephants have a strong distaste towards chilli and do not eat them. Crops such as watermelon and Mangalore cucumber were also raided, but to a lesser extent because of low cultivation (Figure 4).

\section{Number of crop-raiding incidents versus distance from the BNP boundary}

Among the 30 croplands that were surveyed, majority were at a distance of $2 \mathrm{~km}$ from the forest, followed by

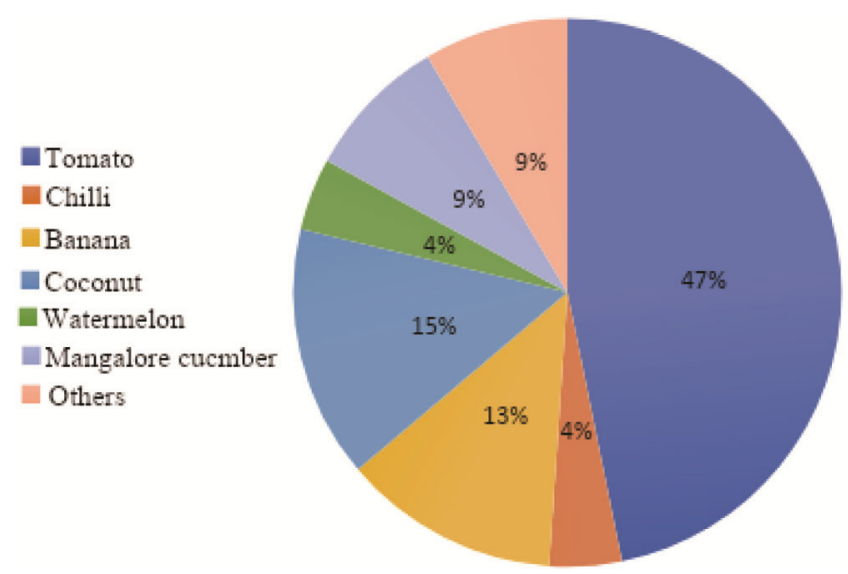

Figure 4. Types of crops destroyed (number of respondents $=30$ ).

Figure 3. Types of crops grown (no. of respondents $=30$ ). 


\section{RESEARCH ARTICLES}

those ranging between 1 and $1.5 \mathrm{~km}$ (Figure 5). Most of the damage was on croplands which were at a distance of $2 \mathrm{~km}$ from the forest (Figure 6). This can be supported by the fact that eight of the croplands which were at $2 \mathrm{~km}$ from the forest boundary grew crops such as tomato, banana, coconut, Mangalore cucumber, watermelon and mango, which are favourable for the elephants. Around three croplands were at only $50 \mathrm{~m}$ to $500 \mathrm{~m}$ from the forest boundary, but their damage was relatively less. This is justified based on the fact that majority of croplands are far away from the forest. In the immature stage, fields farther from the forest edge showed higher damaged areas than those closer to the forest edge ${ }^{21}$. A study conducted in the Shivapuri National Park, Nepal found that there was an abrupt decrease in crop damage from near to middle type of access (15-30 min walk; 0.5-1 km), but there was no difference between middle and far access ( $>30$ min walk; $>1 \mathrm{~km}$ ). This shows that mean crop damage decreases with respect to increase in access to the forest $^{22}$. It is also possible for elephants to wander farther into the croplands in search of crops they normally prefer to eat.

\section{Damage to fencing}

In several croplands, poles were broken along with fencing wires and gates. Elephants learn quickly that their

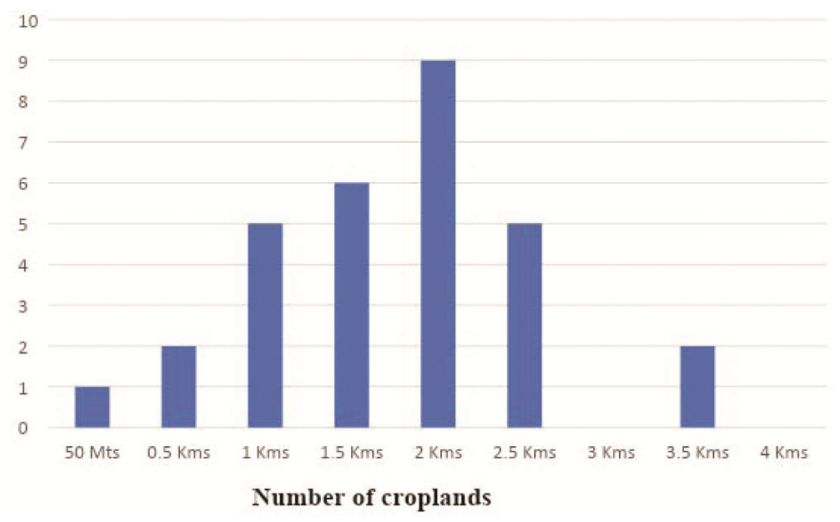

Figure 5. Distance between croplands and forest boundary (number of respondents $=30$ ).

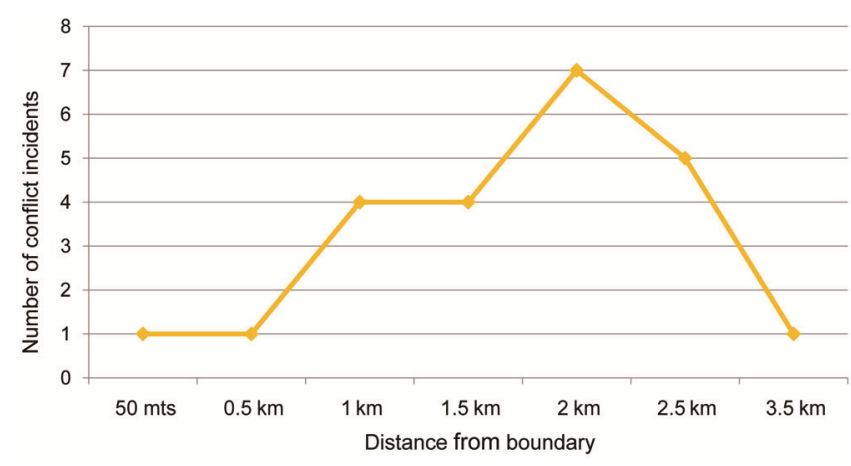

Figure 6. Distance versus number of incidents. tusks do not conduct electricity and so use them to break down fences (fence-breakers) ${ }^{23}$. They also break the wires and push down posts using their feet ${ }^{24}$. Damages were caused mainly because of less voltage in the battery to feed enough power supply to the fence lines and improper maintenance. Raids happened more often when the batteries were not in good condition. Problems related to battery usually arise when the maintenance is poor. If the fence is well-maintained, the animals will always receive a shock when they touch it. This will condition them not to challenge the fence. If the fence is not in a good condition and is not working during a raid, the elephants will try to break the fence since it acts as a weak barrier ${ }^{25}$. Seasons also play a role in damaging fencing. Extensive damage occurs during the rainy season and lightning can cause serious damage to the energizer (Figure 7).

Out of 30 people interviewed, $83 \%$ mentioned that the solar fence was useful in protecting the crops, while $16 \%$ said that the fence was not useful. The remaining $1 \%$ mentioned that the fence prevented crop raids, but it was not helpful all the time. Prior to the use of solar fence, landowners used to guard their croplands every night in tents or by sitting on treetops, which was often unsafe. They consider that installing solar fences has brought about a positive change in terms of their safety and crop protection.

\section{Year of installation}

The year of installation determines the condition of the fencing. About $6 \%$ of croplands had solar fence installed 20 years ago. Majority of the croplands had installed solar fencing during 2016-2018 (Figure 8). We observed that the fencing which was installed in 1998 eventually grew weak. Their batteries had to be replaced several times and the croplands were prone to more raids during the period when the batteries were dysfunctional. The damage caused due to these raids also increased with time since installation of the fence. Fences that were installed recently had fewer battery problems and worked more

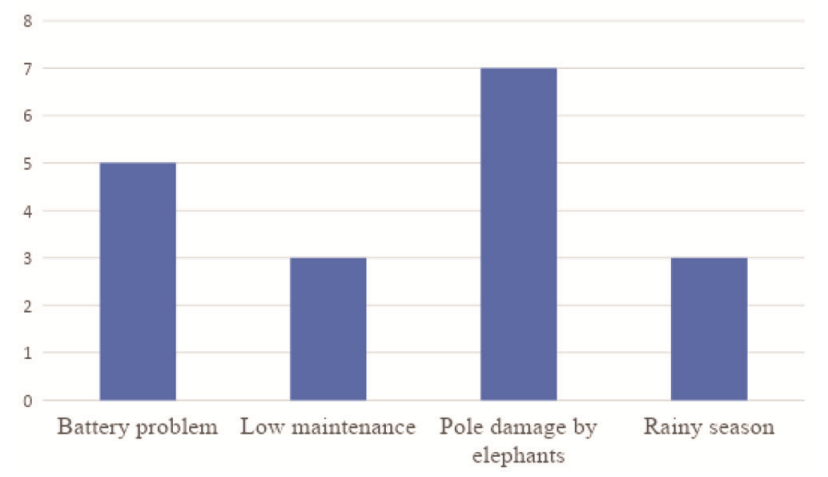

Figure 7. Types of damage to solar fence observed in the study area (number of respondents $=30$ ). 


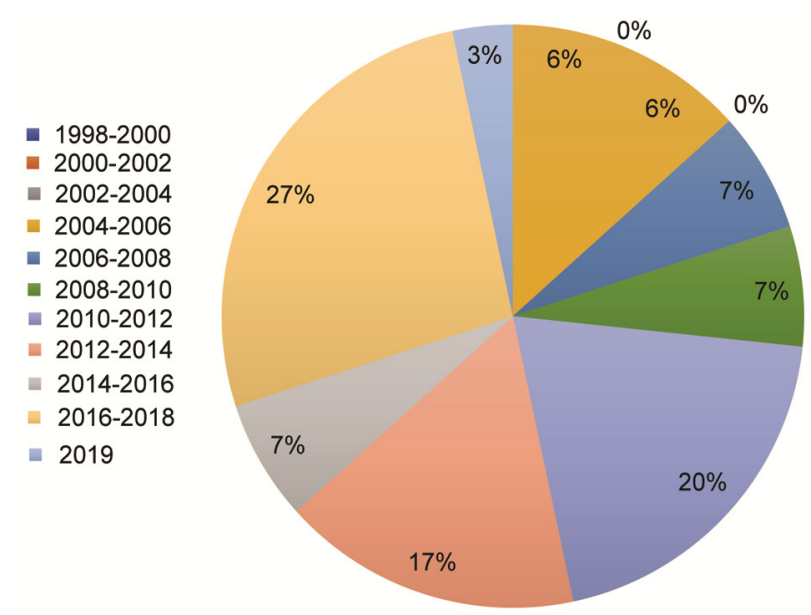

Figure 8. Year of installation of solar fence (number of respondents $=30)$.

efficiently. Around five croplands which had fencing installed recently were not raided by elephants. Although a few fencing poles were damaged, the total loss was significantly less.

\section{Conclusion}

HECs have become a major concern over the last few years in the country. It is because of the ever-increasing human population and insignificant land use. This has led to decrease in the loss of habitat of elephants, resulting in the rise in HECs. There are several mitigation measures, but these cannot completely end HECs. Solar fencing plays a major role in eliminating such conflicts; it has the advantages of being conventional and easily accessible. The present study highlights the conflict status in Manchahalli village, Karnataka. To solve the problem prevailing in the area, we recommend the following measures: (i) Subsidy system should be promoted by the government to install fences. (ii) Monetary help to farmers to maintain solar fences. (iii) Creating awareness among the farmers about agroforestry, so that their income is protected.

1. Oswin Perera, B. M. A., The human-elephant conflict: a review of current status and mitigation methods. Gajaha, 2009, 30, 41-52.

2. Desai, A. A. and Riddle, H. S., Human Elephant Conflict in Asia, Report to U.S. Fish and Wildlife Service, 2015.

3. Chakraborty, S., Boominathan, D. and Desai, A. A., Using genetic analysis to estimate population size, sex ratio, and social organization in an Asian elephant population in conflict with humans in Alur, southern India. Conserv. Genet., 2014, 15, 897-907.

4. Ranjan, K. B. and Nabami, B., A comprehensive study of humanelephant conflict in the bordering areas of the three reserve forests of Lakhimpur district, Assam. Int. J. Interdiscip. Res. Sci. Soc. Cult., 2016, 2(1).

5. Senthilkumar, K., Mathialagan, P., Manivannan, C., Gomathinayagam, S. and Jayathangara, G., Human-elephant conflict: case study from Tamil Nadu. Int. J. Sci., Environ. Technol., 2017.

6. Bal, P., Nath, D. and Garcia, C., Drivers of human-elephant interactions in coffee agroforestry landscapes in Kodagu (Western Ghats), India, 2008.
7. Ramkumar, K., Ramakrishnan, B. and Saravanamuthu, R., Human-elephant conflict in southern India: people's perception on conflict and elephant conservation in Coimbatore Forest Division. J. Sci. Trans. Environ. Technol., 2013, 7(2), 69-76.

8. Osborn, F. V. and Parker, G. E., Towards an integrated approach for reducing the conflict between elephants and people: a review of current research. Oryx, 2003, 37(1), 80-84.

9. Gunaratne, L. H. P. and Premarathne, P. K., The effectiveness of electric fencing in mitigating human-elephant conflict in Sri Lanka, 2006.

10. Kumar, A., Bargali, Harendra, S., David, A and Edgaonkar, A., Patterns of crop rading by wild ungulates and elephants in Ramnagar Forest Division, Uttarakhand. Human-Wildl. Interact., 2017, 11(1), 41-49.

11. Sukumar, R., Elephant-human conflict in Karnataka. In Karnataka State of the Environment Report (ed. Saldanha, C. J.), 1986, pp. 46-59.

12. Bal, P., Nath, C. D. and Nanaya, K. M., Elephants also like coffee: trends and drivers of human-elephant conflicts in coffee agroforestry landscapes of Kodagu, Western Ghats, India. Environ. Manage., 2011, 47, 789-801.

13. Jener, W. G., Electric fencing. Report submitted to the Dept of Elect. and Info. Engineering, University of Nairobi, 2011.

14. Sridevi, S. N. and Reddy, V., Human-elephant conflict in Tumkur district, Karnataka, India. Int. J. Life Sci., 2018, 6(2), 625-634.

15. Khanum, F., Swamy, M. S., Sudarshana, K. K. R., Santhanam, K. and Viswanathan, K. R., Dietary fibre content of commonly fresh and cooked vegetables consumed in India. Plant Foods Hum. Nutr., 2000, 55, 207-218.

16. Sangamithra, A., Swamy, G. J., Sorna, P. R., Chandrasekar, V., Sasikala, S. and Hasker, E., Coconut: an extensive review on value added products. Indian Food Ind. Mag., 2013, 32(6), 29-36.

17. Simmonds, N. W., The Evaluation of Bananas, Tropical Science Series, Longmans, London, UK, 1962.

18. Sampath, K. K., Ekanayaka, A., Campos-Arceiz and Fernando, P., Patterns of crop raiding by Asian elephants in a human-dominated landscape in southeastern Sri Lanka. Gajah, 2011, 34, 20-25.

19. Bhandara, R. and Tisdell, C., Asian elephants as agricultural pests: damages, economics of control and compensation in Sri Lanka. Economics, Ecology and Environment Working Papers 48735, University of Queensland, School of Economics, 2002.

20. Ankur, K., Harendra, S. B., Ashish, D. and Advait, E., Humanwildlife interactions patterns of crop raiding by wild ungulates and elephants in Ramnagar Forest Division, Uttarakhand. Spring, 2017, 11(1), 41-49.

21. Sudip, P. and Siddhartha, B. B., Crop protection and its effectiveness against wildlife: a case study of two villages of Shivapuri National Park, Nepal. J. Sci. Technol., 2015, 16(1), 110.

22. Graham, M. D., Gichohi, N., Kamau, F., Aike, G. and Craig, B., The use of electrified fences to reduce human-elephant conflict: a case study of the Ol Pejeta Conservancy, Laikipia District, Kenya, Working Paper 1, Laikipia Elephant Project, Nanyuki, Kenya, 2009.

23. John, K., Philip, M., Patrick, O. and Patrick, I. C., The performance of electric fences as elephant barriers in Amboseli, Kenya, 2007.

24. Lamarque, F., Anderson, J., Fergusson, R. and Lagrange, M., Human-wildlife conflict in Africa: causes, consequences and management strategies. Food and Agriculture Organization of the United Nations, Rome, Italy, 2009.

25. Neupane, B., Khatiwoda, B. and Budhathoki, S., Effectiveness of solar powered fence in reducing Human-Wild Elephant Conflict (HEC) in Northeast Jhapa District, Nepal. Forestry: J. Inst. Forest., 2018, 15, 13-27.

Received 12 June 2019; revised accepted 16 October 2020

doi: $10.18520 / \mathrm{cs} / \mathrm{v} 120 / \mathrm{i} 4 / 707-711$ 